\title{
Identifying patterns of unhealthy diet and physical activity in four countries of the Americas: a latent class analysis
}

\author{
Sahara Graf ${ }^{1}$ and Michele Cecchini²
}

Suggested citation

Graf S, Cecchini M. Identifying patterns of unhealthy diet and physical activity in four countries of the Americas: a latent class analysis. Rev Panam Salud Publica. 2018;42:e56. https://doi.org/10.26633/ RPSP.2018.56

ABSTRACT Objectives. To determine clusters of individuals who present similar health behaviors in terms of diet, physical activity, and sedentarism, in four countries of the Americas: Brazil (2013), Chile (2009), Mexico (2012), and the United States of America (2013). This makes it possible to determine which of these behaviors occur simultaneously, as well as the demographic and sociodemographic characteristics associated with each cluster.

Methods. The individual-level data analyzed were drawn from national health interviews and health examination surveys in Brazil, Chile, Mexico, and the United States, for different time periods. Using international physical activity guidelines and national dietary guidelines, the health behaviors of each individual were assessed. A latent class analysis was conducted to classify individuals into clusters based on these behaviors, and was followed by multinomial regressions to determine the characteristics of those in each class.

Results. Overall, most individuals belonged to the classes characterized by average or unhealthy diets but sufficient amounts of physical activity. However, large differences exist across countries and population groups. Men with higher socioeconomic characteristics were globally more likely to belong to the least healthy class in each country.

Conclusions. Findings from this analysis support the implementation of more refined policy actions to target specific unhealthy behaviors in different population groups, defined by gender, age group, socioeconomic status, and, to some extent, place of residence. The at-risk populations identified through this paper are those that should be targeted by upcoming interventions.

Keywords Epidemiology; diet; life style; exercise; Americas.

In recent decades, unhealthy lifestyles have fueled an epidemic of noncommunicable diseases (NCDs) that are now the first cause of health burden worldwide (1). In the Americas, it is estimated that over 200 million people are living with

\footnotetext{
Consultant, Villeneuve d'Ascq, France.

2 Organisation for Economic Co-operation and Development, Health Division, Paris, France. Send correspondence to Michele Cecchini at michele.cecchini@oecd.org
}

an NCD, and that NCDs are associated with $79 \%$ of all deaths (2). The prevalence of diabetes, cardiovascular diseases, and other chronic diseases has increased significantly, particularly in Latin American countries (3). Meanwhile, diet quality has deteriorated, and physical activity (PA) has not risen, despite an increasing volume of public policies (4).

Lack of PA, high amounts of sedentary behavior (SB), and low-quality diet are well-known key risk factors for NCDs (1). These behaviors have a dual effect. In addition to being key risk factors for NCDs, they are also key risk factors for obesity (3), which in turn can lead to NCDs. In 2014, approximately $58 \%$ of the adult population in Latin America and the Caribbean was overweight, including $23 \%$ of obese people (5). Overweight affects over $50 \%$ of the population in nearly all the countries of Latin America 
and the Caribbean. In 2015, high body mass index (BMI) led to over 4.5 million deaths worldwide (1). This double pathway to NCDs makes prevention of these risk factors all the more crucial. This is especially true since healthy dietary choices and PA have all been proven to be effective in the prevention and treatment of NCDs (6).

Tackling major risk factors or NCDs requires more than a single preventive intervention; fundamental change can only occur through wide-ranging strategies that address multiple determinants of health (such as diet and PA) (7). Furthermore, cost-effectiveness of a preventive measure is typically improved by targeting a high-risk population (8). This increases the proportion of individuals who benefit and therefore the health benefits gained per unit of money spent.

Policies must be tailored to fit the needs of specific groups of people, to target multiple specific behaviors that may vary across the population. These unhealthy behaviors, as well as the subpopulations that exhibit these behaviors, are likely to be country-dependent. Therefore, tailoring prevention policies to meet the needs of different countries is key.

This paper aims to identify high-risk groups, that is, ones that are most likely to exhibit unhealthy dietary behaviors, lack of PA, or excessive SB, as well as the characteristics that define them, in four countries of the Americas: Brazil (2013), Chile (2009), Mexico (2012), and the United States of America (2013). Findings from this paper can be used to inform the tailoring of prevention policies in these countries and to increase the effectiveness and cost-effectiveness of population-based actions to tackle unhealthy behaviors and associated NCDs.

\section{MATERIALS AND METHODS}

\section{Data}

The analyses undertaken in the following article are based on individual data, which were drawn from national health interviews and health examination surveys from Brazil, Chile, Mexico, and the United States. The data for Brazil were drawn from the Pesquisa Nacional de Saúde (National Health Survey) (PNS) 2013. The dataset for Chile includes data from the Encuesta Nacional de Salud (National Health Survey) (ENS), and refers to survey year 2009. Mexican data is from the Encuesta Nacional de Salud y Nutrición (National Health and Nutrition Survey) (ENSANUT) 2012. Finally, the database for the United States includes the data from the National Health and Nutrition Examination Survey (NHANES) of 2013. The analyses were performed using self-reported data on dietary behaviors, PA, and SB.

Dietary habits were surveyed either through a 24-hour recall (United States) or food frequency questionnaires (Brazil, Chile, and Mexico). The 24-hour recall makes it possible to record precise data on types and amounts of food consumed, and from that extract daily nutrient intakes. The food frequency questionnaires assess the frequency with which different foods are consumed, on a daily or weekly basis. The foods included in the questionnaires differ by country. These two approaches are validated, and are widely used (9).

The PA questionnaires used in the different surveys resemble the General Physical Activity Questionnaire (GPAQ) (10), which was used for the NHANES, or the International Physical Activity Questionnaire (IPAQ) (11). Depending on the country, PA was surveyed either globally, without breaking it down into categories, or by domain (leisure, transport-related, work-related, and domestic and gardening). Most questionnaires also survey the intensity of the PA (vigorous or moderate). SB was surveyed similarly for Chile, Mexico, and the United States, by asking the length of daily sedentarism on a "usual day." For Brazil, only daily television time was available, which we used as a proxy.

\section{Statistical analysis}

Our analysis is based on latent class analysis (LCA). LCA is a statistical technique that is used to sort individuals from a heterogeneous population into homogenous unobservable (latent) classes. The algorithm uses observable variables (manifest variables) to separate individuals into groups of people who share similar characteristics, by searching for the most frequent and similar patterns among the distributions of these variables. The technique produces latent class membership probabilities, which list the probability of belonging to each latent class, and the item-response probabilities, which list the probability of possessing a certain manifest characteristic conditional on latent class membership. These probabilities are model based: they depend on the model specification and estimated parameters, and are therefore called posterior probabilities. LCA has been used to study the clustering of risky behaviors in young people (12), epidemiologic outcomes (13), and PA and SB (14).

Variables concerning PA, SB, and diet were used as the manifest variables. PA was assessed by determining whether the World Health Organization (WHO) recommendations were met or not (15). Sedentarism was assessed by determining whether daily SB was seven hours or more, as risk of mortality increases significantly beyond this threshold (16). Consistent with previous studies (17), for Brazil we established that an individual exhibited excess SB if daily television watching time was three hours or more. Diet was evaluated differently depending on the country. We followed the most recent national guidelines pertaining to each country included: Brazil (18), Chile (19), Mexico (20), and the United States (21).

To ensure that the best fitting latent class model was selected for each country, models running from two to six classes were estimated and compared. The analysis produces the Akaike Information Criterion (AIC), the Bayesian Information Criterion (BIC), the Adjusted Bayesian Information Criterion (ABIC), the Consistent Akaike Information Criterion (CAIC), as well as the $\mathrm{G}^{2}$, which is a likelihood-ratio $\chi^{2}$ statistic that is similar to the more renowned Pearson $\chi^{2}$. The $\mathrm{AIC}$ and BIC represent relative model fit. Previous work shows that the AIC tends to overestimate the number of classes necessary, while the BIC tends to underestimate it (22). The ABIC adjusts on sample size (23). When studying larger samples, the most likely error is overfitting, and it is best to use a more parsimonious criterion such as the BIC (24); furthermore, the CAIC has been shown to behave similarly to the BIC in several simulations (25). As the samples used for our analyses were large ( $\mathrm{N}>2000$ for all datasets), our models were chosen based on the BIC and CAIC, as well as overall interpretability of the resulting classes.

Additionally, 200 randomly selected seeds were used to estimate each model. The analysis produces the percentage of seeds associated with the best fitted model, 
which is the percentage of iterations resulting in the highest log-likelihood. This number indicates whether the resulting model most likely represents a local maximum (low percentage), or a global maximum (high percentage). A higher percentage indicates that the model appears well identified (26). Entropy (between 0 and 1) indicates level of separation of classes; higher levels of entropy indicate better separation of latent classes. Weights were used for all analyses, and were standardized through the LCA plug-in.

After the LCAs were completed, multinomial logistic regressions were run, using latent class membership as the dependent variable. The regressions were conducted outside the scope of the LCA plug-in, as this method was less time-consuming, and has been used in other studies (14). Individuals were assigned to the latent class for which they had the highest latent class membership probability. Age, gender, socioeconomic status (SES), education level, level of BMI as identified by WHO thresholds (27), a geographic variable (apart from for the United States), and ethnicity (United States only) were included in the regressions.

For Brazil and Chile, the geographic variable indicates whether an individual lives in a urban or rural area. For Brazil, the variable was extracted from the original national health survey database. For Chile, the variable was created using data from the National Statistics Institute (Instituto Nacional de Estadísticas) (28); regions whose rural population was higher than the national average were considered to be rural, while those whose rural population was lower were considered to be urban. For Mexico, the variable used was included in the original database, and establishes a region as rural, urban, or metropolitan. No regional variables were available for the United States; however, an ethnicity variable was included in the analysis: non-Hispanic white, non-Hispanic black, Mexican-American, and other ethnicity.

For variables with a trend (level of education, SES, age), the reference chosen for the regressions is the middle category. After running the regressions, the relative risk ratios (RRRs) were studied. RRRs are comparable to odds ratios, as they are the exponentiated parameters resulting from the regressions.

All analyses were undertaken with the Stata/MP 14.1 software package. The LCAs were carried out using the
DoLCA plug-in from the Methodology Center at Penn State University (29). This plug-in produces maximum likelihood estimates for parameters using the "expectation-maximization" (EM) algorithm. It constructs the classes and produces the class membership probabilities and item-response probabilities. All observations containing missing data for the manifest variables were removed before estimation.

\section{RESULTS}

A total of 36316 individuals for Brazil, 4770 for Chile, 2222 for Mexico, and 6239 for the United States were included in the study. To strengthen the analysis, no individuals were excluded on the basis of age. The data for Brazil refer to ages 18-90; the data for Chile refer to ages 15100 ; the data for Mexico refer to ages 2069; and the data for the United States refer to ages 12-80.

Across the different samples, men are more numerous only in Brazil (Table 1). In all countries, a larger share of the population has high SES, while a low or medium level of education is most prominent in Brazil, Chile, and Mexico. In the United States, non-Hispanic white people represent the largest share of the sample, followed by people of other ethnicities, non-Hispanic black people, and Mexican American individuals. Those living in rural areas represent $41 \%$ of the sample or less in all countries. In all countries, the majority of individuals (between $57.0 \%$ and $70.3 \%$ ) are overweight or obese. Mexico and the United States have the highest levels of obesity. More than half the population report meeting the WHO recommendations for PA in Chile, Mexico, and the United States, while in Brazil fewer than 30\% reach the target. In Brazil, Chile, and Mexico, most of the population displays low SB, while in the United States less than $50 \%$ of the sample does so.

The item-response probabilities resulting from the latent class analyses represent the probability for a member of a latent class of meeting or exceeding the recommendations in terms of diet, PA, or SB. For instance, if the item-response probability for high fruit and vegetable (FV) consumption in class 1 is 0.15 , as is the case for class 1 in Brazil, then there is a $15 \%$ chance that a member of class 1 consumes at least the recommended minimum amount of FV. Therefore, a higher percentage for $\mathrm{FV}$ is positive, but a higher percentage for sodium (for instance, class 1 in the United States) is negative. These item-response probabilities are what are used to define and label the different latent classes.

Supplementary Annex Table 1 displays the descriptive statistics for the key variables of the study by country and latent class. It must be noted that the share of individuals in each latent class, as well as the share of health-related behaviors, are not the ones used to identify and label the different latent classes, as they are simple weighted descriptive statistics and not probabilities. This explains why the rates do not always match the latent class membership and item-response probabilities presented below.

The choice of optimal number of latent classes for each country was based on the fit statistics resulting from the analysis (Annex Table 2), as well as overall interpretability of the classes.

The diet, PA, and SB patterns in each latent model differ by country (Figure 1). However, overall, classes are characterized by high probabilities of PA and low probabilities of $\mathrm{SB}$, with the exception of one class in Chile, Mexico, and the United States, in which PA is low and SB is high, as well as two classes in Brazil, in which PA is low but so is SB. In each country, a least healthy latent class can be identified (class 1 in all countries), based on the probabilities of PA, sedentarism, and dietary behaviors. However, healthiest classes can be more difficult to pinpoint, as the balance between good quality diet and levels of PA/SB can be difficult to establish.

The final models chosen for Brazil, Chile, and Mexico have three classes, while the final model for the United States has four classes.

The models for Chile and Mexico are comparable (Panels b and c): one class with a rather unhealthy diet, a low probability of sufficient PA and high probability of excessive SB (class 1); one class that displays a poor quality diet, but healthy levels of PA and SB (class 2); and a final class that is clearly the healthiest, with a high probability of PA, a low probability of SB, and a healthy diet (class 3). For both countries, the second class has the highest membership probability $(82 \%)$, while the third class represents $14 \%$ and $13 \%$ of the sample in Chile and Mexico, respectively, and the first class represents $4 \%$ and $5 \%$, respectively. 
TABLE 1. Descriptive statistics for Brazil (2013), Chile (2009), Mexico (2012), and the United States (2013), in study of patterns of unhealthy diet and physical activity

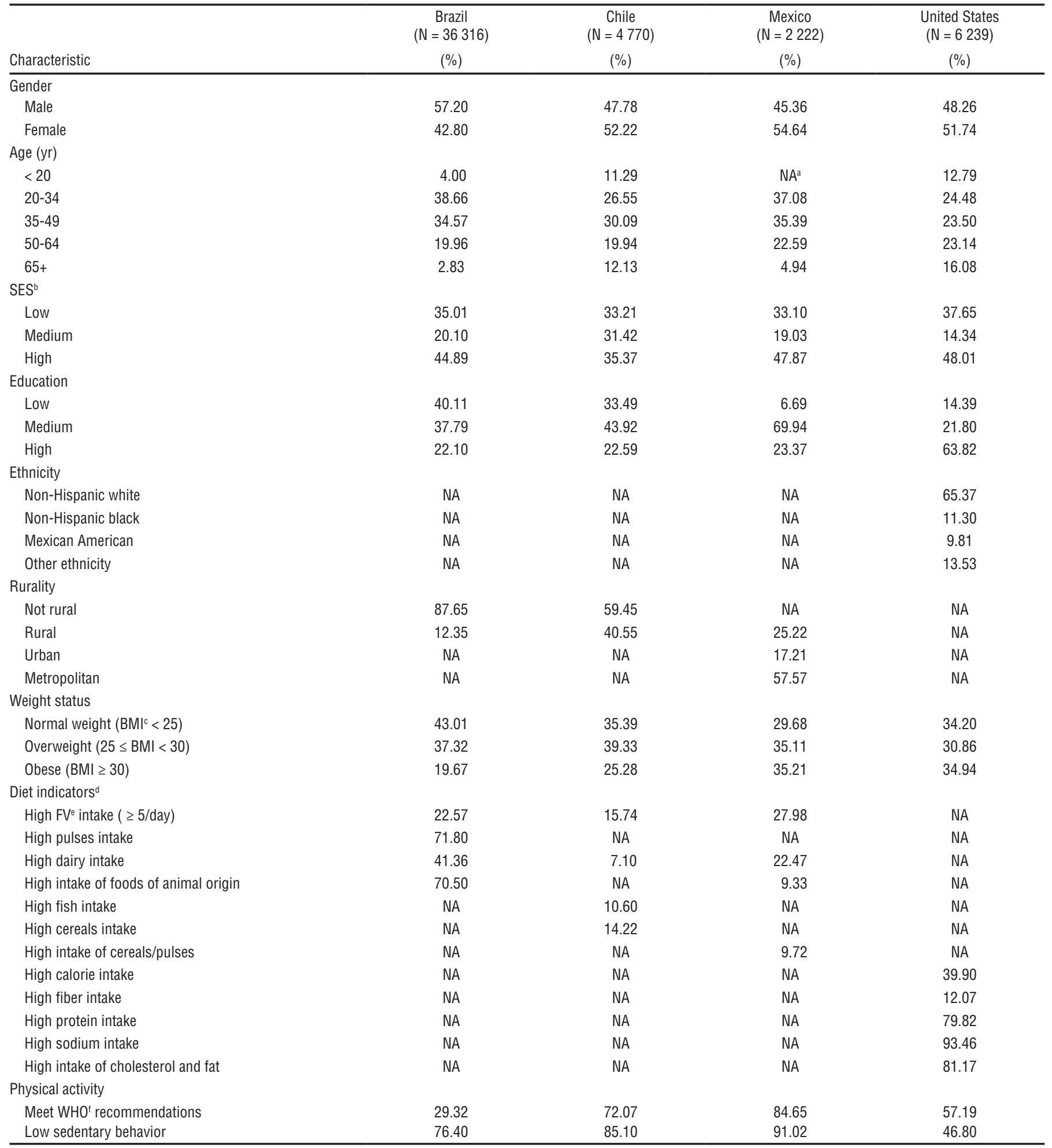

Source: Prepared by the authors based on the study results.

${ }^{\mathrm{a}} \mathrm{NA}=$ not applicable

${ }^{\mathrm{b}} \mathrm{SES}=$ socioeconomic status.

${ }^{\mathrm{C}} \mathrm{BMI}=$ body mass index.

${ }^{d}$ Descriptive statistics for diet indicators express whether consumption meets or exceeds recommendations.

${ }^{\mathrm{e}} \mathrm{FV}=$ fruits and vegetables.

${ }^{\mathrm{f}} \mathrm{WHO}=$ World Health Organization 
TABLE 2. Results from multinomial regressions on latent class membership in Brazil, Chile, Mexico, and the United States ${ }^{a}$

\begin{tabular}{|c|c|c|c|c|c|c|c|c|}
\hline \multirow[b]{2}{*}{ Class/Characteristic } & \multicolumn{2}{|c|}{ Brazil (N = 35762$)$} & \multicolumn{2}{|c|}{ Chile (N = 4 639) } & \multicolumn{2}{|c|}{ Mexico (N = 2122$)$} & \multicolumn{2}{|c|}{ United States $(\mathrm{N}=4628)$} \\
\hline & $\mathrm{RRR}^{\mathrm{b}}$ & $\mathrm{SE}^{\mathrm{c}}$ & RRR & SE & RRR & SE & RRR & SE \\
\hline Class 1 & Ref. $^{d}$ & & Ref. & & Ref. & & Ref. & \\
\hline \multicolumn{9}{|l|}{ Class 2} \\
\hline \multicolumn{9}{|l|}{ Gender } \\
\hline Male & Ref. & & Ref. & & Ref. & & Ref. & \\
\hline Female & 1.05 & 0.12 & 0.96 & 0.21 & $3.05^{\star \star \star}$ & 0.85 & 1.16 & 0.16 \\
\hline $20-34$ & 0.94 & 0.12 & 0.92 & 0.34 & 0.77 & 0.26 & 1.00 & 0.20 \\
\hline $35-49$ & Ref. & & Ref. & & Ref. & & Ref. & \\
\hline $50-64$ & 0.96 & 0.15 & 0.92 & 0.30 & 0.92 & 0.38 & $0.63^{*}$ & 0.12 \\
\hline $65+$ & $2.34^{\star \star}$ & 0.65 & $0.36^{\star \star \star *}$ & 0.10 & 0.72 & 0.49 & 0.91 & 0.17 \\
\hline \multicolumn{9}{|l|}{ SES $^{\dagger}$} \\
\hline Low & $0.72^{*}$ & 0.11 & $0.62^{*}$ & 0.14 & 0.75 & 0.56 & 1.41 & 0.28 \\
\hline Medium & Ref. & & Ref. & & Ref. & & Ref. & \\
\hline High & $0.68^{\star \star}$ & 0.09 & 0.71 & 0.23 & $0.33^{* *}$ & 0.11 & 0.88 & 0.15 \\
\hline \multicolumn{9}{|l|}{ Rurality } \\
\hline Not rural & Ref. & & Ref. & & NA & & NA & \\
\hline Rural & $0.50^{\star * *}$ & 0.10 & 1.21 & 0.28 & 1.77 & 0.66 & NA & \\
\hline Urban & NA & & NA & & 1.19 & 0.49 & NA & \\
\hline Metropolitan & NA & & NA & & Ref. & & NA & \\
\hline \multicolumn{9}{|l|}{ Ethnicity } \\
\hline Non-Hispanic white & NA & & NA & & NA & & Ref. & \\
\hline Male & Ref. & & Ref. & & Ref. & & Ref. & \\
\hline Female & $1.38^{\star \star \star}$ & 0.11 & $2.46^{\star \star}$ & 0.75 & $2.37^{\star}$ & 0.82 & $0.67^{\star \star \star}$ & 0.08 \\
\hline \multicolumn{9}{|l|}{ Age group (yr) } \\
\hline$<20$ & 1.42 & 0.29 & $0.37^{\star}$ & 0.17 & NA & & NA & \\
\hline $20-34$ & 1.08 & 0.09 & 0.86 & 0.41 & 0.69 & 0.28 & $1.63^{\star *}$ & 0.25 \\
\hline $35-49$ & Ref. & & Ref. & & Ref. & & Ref. & \\
\hline $50-64$ & 1.06 & 0.11 & 1.66 & 0.73 & 1.08 & 0.51 & 0.81 & 0.12 \\
\hline $65+$ & 1.23 & 0.27 & 0.89 & 0.41 & 0.50 & 0.45 & 0.79 & 0.12 \\
\hline \multicolumn{9}{|l|}{ SES } \\
\hline Low & 1.16 & 0.14 & 0.54 & 0.19 & 0.95 & 0.48 & 0.88 & 0.16 \\
\hline Medium & Ref. & & Ref. & & Ref. & & Ref. & \\
\hline High & $1.50^{\star * *}$ & 0.17 & 0.82 & 0.30 & 0.74 & 0.33 & 0.81 & 0.15 \\
\hline \multicolumn{9}{|l|}{ Education } \\
\hline Low & $0.60^{\star * *}$ & 0.06 & $0.42^{*}$ & 0.15 & 0.34 & 0.31 & $1.51^{*}$ & 0.26 \\
\hline Medium & Ref. & & Ref. & & Ref. & & Ref. & \\
\hline High & $2.33^{\star \star *}$ & 0.21 & 0.93 & 0.39 & 0.97 & 0.37 & 1.13 & 0.16 \\
\hline
\end{tabular}


TABLE 2. Continued

\begin{tabular}{|c|c|c|c|c|c|c|c|c|}
\hline \multirow[b]{2}{*}{ Class/Characteristic } & \multicolumn{2}{|c|}{ Brazil $(\mathrm{N}=35762)$} & \multicolumn{2}{|c|}{ Chile $(\mathrm{N}=4639)$} & \multicolumn{2}{|c|}{ Mexico (N = 2122$)$} & \multicolumn{2}{|c|}{ United States $(N=4628)$} \\
\hline & $\mathrm{RRR}^{\mathrm{b}}$ & $\mathrm{SE}^{\mathrm{c}}$ & RRR & SE & RRR & SE & RRR & $\mathrm{SE}$ \\
\hline \multicolumn{9}{|l|}{ Rurality } \\
\hline Not rural & Ref. & & Ref. & & NA & & NA & \\
\hline Rural & 0.88 & 0.10 & 0.74 & 0.24 & 1.77 & 0.77 & NA & \\
\hline Urban & NA & & NA & & 0.61 & 0.28 & NA & \\
\hline Metropolitan & NA & & NA & & Ref. & & NA & \\
\hline Non-Hispanic black & NA & & NA & & NA & & 0.89 & 0.12 \\
\hline Mexican American & NA & & NA & & NA & & 1.32 & 0.24 \\
\hline Other ethnicity & NA & & NA & & NA & & $1.35^{\star}$ & 0.19 \\
\hline Constant & $0.05^{\star * *}$ & 0.0056 & 1.17 & 0.52 & 2.37 & 1.16 & $2.66^{* \star *}$ & 1.15 \\
\hline Class 4 & NA & & NA & & NA & & & \\
\hline$<20$ & NA & & NA & & NA & & NA & \\
\hline $20-34$ & NA & & NA & & NA & & 1.33 & 0.21 \\
\hline $35-49$ & NA & & NA & & NA & & Ref. & \\
\hline $50-64$ & NA & & NA & & NA & & 0.81 & 0.13 \\
\hline $65+$ & NA & & NA & & NA & & $0.66^{* *}$ & 0.11 \\
\hline \multicolumn{9}{|l|}{ SES } \\
\hline Low & NA & & NA & & NA & & 0.80 & 0.14 \\
\hline Medium & NA & & NA & & NA & & Ref. & \\
\hline High & NA & & NA & & NA & & 0.72 & 0.13 \\
\hline \multicolumn{9}{|l|}{ Education } \\
\hline Low & NA & & NA & & NA & & 1.20 & 0.21 \\
\hline \multicolumn{9}{|l|}{ Ethnicity } \\
\hline Non-Hispanic white & NA & & NA & & NA & & Ref. & \\
\hline Non-Hispanic black & NA & & NA & & NA & & 1.02 & 0.13 \\
\hline Mexican American & NA & & NA & & NA & & $1.63^{* *}$ & 0.30 \\
\hline Other ethnicity & NA & & NA & & NA & & 1.14 & 0.16 \\
\hline Constant & NA & & NA & & NA & & $3.09^{* \star *}$ & 0.69 \\
\hline
\end{tabular}

Source: Prepared by the authors based on the study results.

${ }^{a}{ }^{*}=$ significant at the $5 \%$ level; ${ }^{* *}=$ significant at the $1 \%$ level; ${ }^{* *}=$ significant at the $0.1 \%$ level.

${ }^{\mathrm{b}} \mathrm{RRR}=$ relative risk ratio.

${ }^{\mathrm{C}} \mathrm{SE}=$ standard error.

${ }^{\mathrm{d}}$ Ref. $=$ reference.

${ }^{e} \mathrm{NA}=$ not applicable, when a certain category or class was not included for a particular country.

${ }^{\dagger} \mathrm{SES}=$ socioeconomic status.

${ }^{9}$ The constant represents the intercept of the model.

Diet quality is overall higher in Brazil than in Chile and Mexico, but the pattern remains similar (Panel a). The third latent class for Brazil (16\% membership probability) is the healthiest, with average levels of FV and dairy consumption, the highest probability of sufficient PA and lowest probability of excessive SB. The two other classes display a low probability of PA, but also a low probability of SB. The first class ( $75 \%$ probability) exhibits the lowest probabilities of FV and dairy consumption, but higher probabilities for consumption of pulses and foods of animal origin. They are also the least likely to be sufficiently physically active. Those in the second class $(9 \%$ probability of membership) are both the biggest eaters and the most sedentary.

For the United States model, nutrients and macronutrients rather than food 
FIGURE 1. Item-response probabilities for various health-related behaviors across latent classes in Brazil (2013), Chile (2009), Mexico (2012), and the United States (2013), in study of patterns of unhealthy diet and physical activity
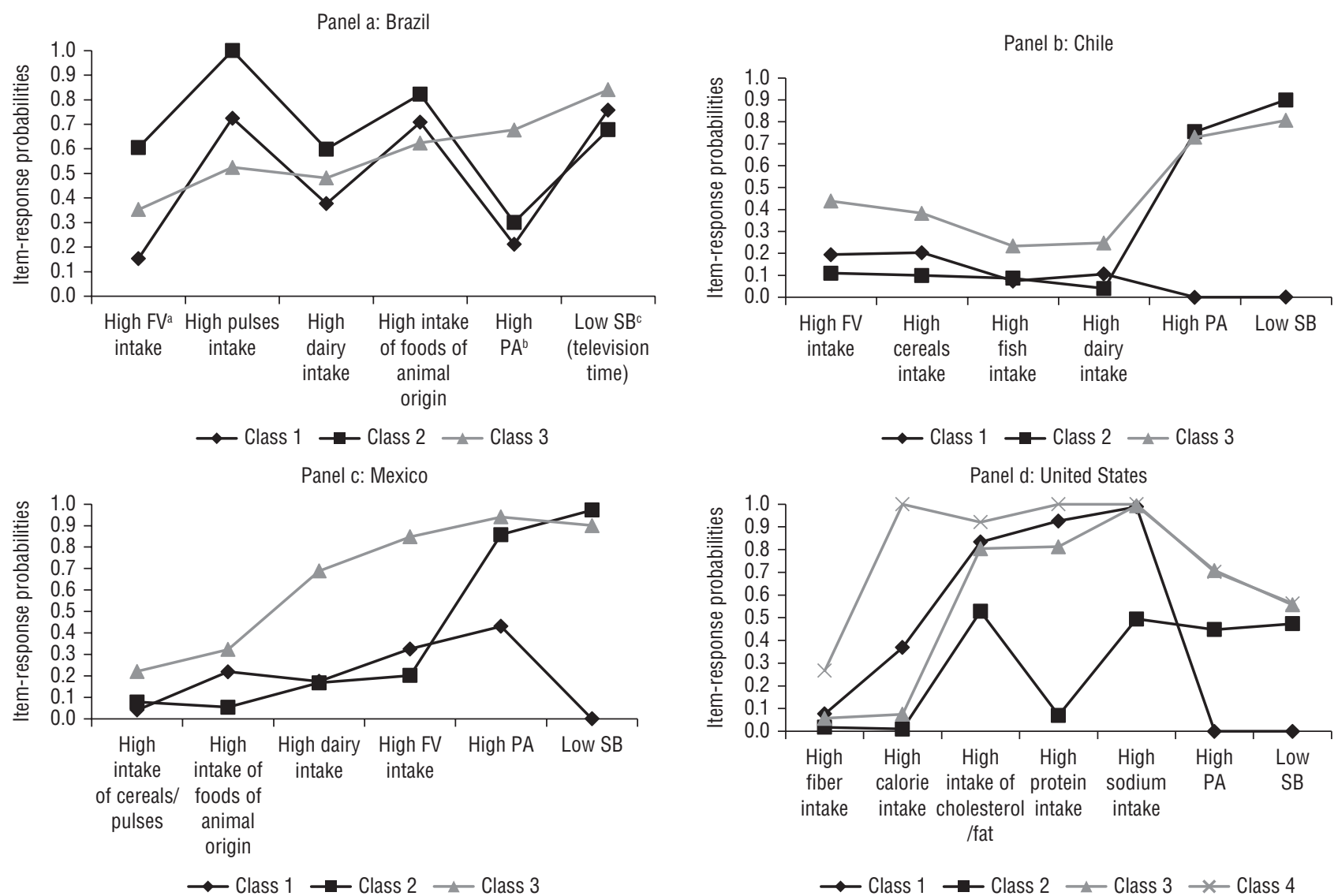

Source: Prepared by the authors based on the study results

a $\mathrm{FV}=$ fruits and vegetables.

bPA = physical activity.

SB = sedentary behavior

TABLE 3. Summary of results, showing population groups with unhealthy dietary and physical activity patterns in Brazil (2013), Chile (2009), Mexico (2012), and the United States (2013)

\begin{tabular}{lll}
\hline Country & Least healthy latent class & Low-quality diet \\
\hline Brazil & Males, under 65, with low education, living in a rural area & Males, under 65, with low education, living in a rural area \\
Chile & Males, under 20 or over 65, with low education, high SES & Aged 20-64, with low or medium SES, medium or high education \\
Mexico & Males, with high education, high SES & Females, with low or medium SES or education \\
United States & Females, over 50, non-Hispanic white & Males, aged 20-34, with low education, of other ethnicity \\
\hline
\end{tabular}

Source: Prepared by the authors based on the study results.

a SES = socioeconomic status.

categories were used to describe diet quality (Panel d). The third and fourth classes (42\% and $31 \%$ probability, respectively) display similar, healthy levels of PA and SB; however, the third class displays low consumption of fiber and calories, while the fourth class has the highest consumption of those two diet indicators. The second class (12\% probability) is characterized by comparably low probabilities of nutrient intakes and PA, while the first latent class (15\% membership probability) displays high probabilities of excessive intake of protein, cholesterol/fat and sodium: virtually no PA: and excessive SB for all its members.

Multinomial regressions made it possible to determine the possible links between latent class membership and other sociodemographic characteristics (Table 2 ). The reference class for each country is the class that was deemed least healthy (class 1 in all countries).
Table 3 reports a summary of results. In Brazil, men under 65 with a low level of education living in a rural area are most likely to display unhealthy patterns of diet and PA. In Chile, men under 20 or over 65 , with low education or high SES, are most at risk for unhealthy diet paired with insufficient PA. In Mexico, men with high SES and education are most likely to present an unhealthy lifestyle, by consuming few healthy foods and by displaying very high levels of SB and low levels 
of PA. In the United States, non-Hispanic white women over the age of 50 are most likely to display unhealthy behaviors.

\section{DISCUSSION}

Results show that, overall, men with higher socioeconomic characteristics are more likely to be in the least healthy latent classes. However, in Brazil, those with low education are more likely to be sorted into the least healthy class, while in the United States, it is women who are more likely to belong to the least healthy latent class. In terms of low-quality diet, those with lower socioeconomic attributes and in younger age groups are most at risk.

In a policy perspective, these at-risk populations are the ones that should be targeted by interventions. In recent years, many countries have been implementing public policies encouraging a healthy lifestyle. These policies include fiscal and pricing measures, transport policies, product reformulation, school-based and worksite interventions, and more (4). Communication policies, such as food labeling, and mass media and social media campaigns, have also been shown to have some impact. Very often, however, these types of measures do not focus on specific population groups but rather target indistinctly the whole population.

Findings from this analysis support the implementation of more refined policy actions to target specific unhealthy behaviors in different population groups, defined by gender, age group, socioeconomic status, and, to some extent, place of residence. Our findings also indicate that, consistently across countries, individuals with a lower socioeconomic status are more likely to have an unhealthy diet. Available evidence suggests that upstream interventions, including community-based interventions and environmental changes, would be particularly effective in modifying dietary behaviors and in tackling obesity in these population groups $(32,33)$. Programs like "Santiago Sano" (34) meet many of the WHO guiding principles for effective interventions to prevent obesity and childhood obesity, such as inclusivity and participation, environmental support, and multisectoral engagement (35). Scaling up the implementation of similar interventions in Latin American countries may further support other ongoing actions to tackle unhealthy behaviors in disadvantaged population groups.

Further work is needed to understand how policy actions can be adapted to target specific population groups and how the effectiveness of interventions varies across population groups. Analyses presented in this paper provide new insights about the clustering of unhealthy healthcare behaviors. However, with few exceptions (e.g. price measures), there is still limited knowledge about how different population groups respond to the same policy action. Future research should focus on understanding which factors influence the effectiveness of policies across population groups and on identifying best practices to maximize the costeffectiveness of interventions.

A latent class analysis was conducted to determine clusters of individuals who present similar health behaviors, and establish their defining characteristics. Unlike traditional cluster analysis, LCA is a finite mixture model, meaning that it builds clusters using a probabilistic model rather than by calculating a distance (such as in principal component analysis or multiple component analysis). The model therefore possesses goodness of fit statistics, rendering evaluation of the model possible.

In LCAs, data are often drawn from small-scale surveys including only a couple hundred individuals. Here, the sample sizes range from 222 (Mexico) to 36316 (Brazil), drawn from nationally representative, internationally recognized regular health surveys, representing four countries of the Americas. Following this study, different behavioral groups in each country, as well as their characteristics, can now be distinguished thanks to the multinomial regressions run after the LCA. Running ordinal multinomial logistic regressions would have led to interesting results as well, but it would have required ordering the latent classes, which we believe would have introduced bias into the analyses.

Some limitations should be noted. The dietary, PA, and SB data used in this study are self-reported. The dietary data were collected through 24-hour recalls (United
States) and food frequency questionnaires (Brazil, Chile, and Mexico). The PA data were retrieved either through the GPAQ (United States) or similar questions. The sedentarism data were retrieved through questions on time spent sitting or on time spent watching TV (Brazil). Self-reported dietary data have some limitations due to underestimation of the intake, recollection bias, and social desirability bias (30). These drawbacks hold for self-reported PA and sedentarism data, which may also be unremarkable, intermittent, or incidental (31). Nonetheless, self-reported data is widely used in the literature (30) as datasets based on objective measures of patterns of diet and PA are virtually nonexistent at the population level.

The latent class analysis was conducted using the national dietary guidelines from the countries studied. The data provided by the surveys sometimes didn't contain all the variables necessary to fully test adherence to the recommendations. For instance, the survey for Chile didn't include information on pulses consumption, while the national guidelines include this item. Nevertheless, we believe sufficient variables were included to correctly assess diet quality.

\section{Conclusions}

The analyses in this paper have established the subpopulations at highest risk for unhealthy lifestyles in four countries, based on their dietary, PA, and sedentarism behaviors. As such, future policy actions aimed at increasing healthy lifestyles should target these groups of individuals.

\section{Conflicts of interest. None declared}

Disclaimer. Authors hold sole responsibility for the views expressed in the manuscript, which may not necessarily reflect the opinion or policy of the RPSP/ $P A J P H$ or PAHO. In addition, the opinions expressed and arguments employed herein do not necessarily reflect the official views of the OECD or of its member countries. Complementary information for this article can be found in OECD Health Working Paper No. 100, which can be downloaded at http://dx.doi. org/10.1787/54464f80-en. 


\section{REFERENCES}

1. Gakidou E, Afshin A, Abajobir AA, Abate $\mathrm{KH}$, Abbafati C, Abbas KM, et al. Global, regional, and national comparative risk assessment of 84 behavioural, environmental and occupational, and metabolic risks or clusters of risks, 1990-2016: a systematic analysis for the Global Burden of Disease Study 2016. Lancet. 2017;390: 1345-422.

2. Hennis A, Ochoa B, Sandoval R. How can Latin America change the course of its 'NCD tsunami'? Available from: https:// www.weforum.org/agenda/2016/06/ is-latin-america-experiencing-a-ncdtsunami/ Accessed on 10 July 2017.

3. Webber L, Kilpi F, Marsh T, Rtveladze K, Brown M, McPherson K. High rates of obesity and non-communicable diseases predicted across Latin America. PLoS One. 2012;7(8):e39589.

4. Organisation for Economic Co-Operation and Development. Obesity update 2017. Paris: OECD Publishing; 2017.

5. Organización de las Naciones Unidas para la Alimentación y la Agricultura; Organización Panamericana de la Salud. 2016 panorama de la seguridad alimentaria y nutricional en América Latina y el Caribe. Santiago: FAO; OPS; 2017.

6. World Health Organization. The global strategy on diet, physical activity and health. Geneva: WHO; 2004.

7. Sassi F, Devaux M, Cecchini M, Rusticelli E. The obesity epidemic: analysis of past and projected future trends in selected OECD countries. (OECD Health Working Papers, No. 45). Paris: Organisation for Economic Co-Operation and Development; 2009.

8. Cohen J, Neumann P, Weinstein M. Does preventive care save money? Health economics and the presidential candidates. $\mathrm{N}$ Engl J Med. 2008;358(7):661-3.

9. Hu F, Rimm E, Smith-Warner S, Feskanich D, Stampfer M, Ascherio A, Sampson L, Willett W. Reproducibility and validity of dietary patterns assessed with a food-frequency questionnaire. Am J Clin Nutr. 1999;69(2):243-9.

10. World Health Organization. Global Physical Activity Questionnaire (GPAQ) analysis guide. Available from http:// www.who.int/ncds/surveillance/ steps/resources/GPAQ_Analysis_Guide. pdf Accessed on 9 March 2017.

11. International Physical Activity Questionnaire Group. Guidelines for data processing and analysis of the International Physical Activity Questionnaire (IPAQ) short and long forms. Available from https: / / docs.google.com/viewer?a= $\mathrm{v} \&$ pid=sites\&srcid=ZGVmYXVsdGRvbWFpbnx0aGVpcGFxfGd4OjE0NDgxMD-
k3NDU1YWRIZTM Accessed on 9 March 2017.

12. Evans-Polce R, Lanza S, Maggs J. Heterogeneity of alcohol, tobacco, and other substance use behaviors in U.S. college students: a latent class analysis. Addict Behav. 2016;53:80-5.

13. Calfee C, Delucchi K, Parsons P, Thompson B, Ware L, Matthay M. Latent class analysis of ARDS subphenotypes: analysis of data from two randomized controlled trials. Lancet Respir Med. 2014;2(8):611-20.

14. Heitzler C, Lytle L, Erickson E, Sirard J, Barr-Anderson D, Story M. Physical activity and sedentary activity patterns among children and adolescents: a latent class analysis approach. J Phys Act Health. 2011;8(4):457-67.

15. World Health Organization. Global recommendations on physical activity for health. Geneva: WHO; 2010.

16. Chau J, Grunseit A, Chey T, Stamatakis E, Brown W, Matthews C, et al. Daily sitting time and all-cause mortality: a meta-analysis. PLoS One. 2013;8(11).

17. Mielke G, Hallal P, Malta D, Lee I. Time trends of physical activity and television viewing time in Brazil: 2006-2012. Int J Behav Nutr Phys Act. 2012;11:101.

18. Organización de las Naciones Unidas para la Alimentación y la Agricultura. El estado de la guías alimentarias basadas en alimentos en América Latina y el Caribe. Roma: FAO; 2014.

19. Instituto de Nutrición y Tecnología de los Alimentos. Guía de alimentación para una vida más sana. Available from http:// www.fao.org/fileadmin/user_upload/ red-icean/docs/Chile_Gu\%C3\%ADa Alimentaria_2013.pdf Accessed on 10 March 2017.

20. Academia Nacional de Medicina. Guías alimentarias y de actividad física en contexto de sobrepeso y obesidad en la población mexicana. México, D.F.: Intersistemas; 2015.

21. Institute of Medicine. Dietary reference intakes for calcium and vitamin D. Washington, D.C: National Academies Press; 2011.

22. McLachlan G, Peel D. Finite mixture models. New York: Wiley; 2000.

23. Sclove S. Application of model-selection criteria to some problems in multivariate analysis. Psychometrika. 1987;52(3):333-43.

24. Dziak J, Coffman D, Lanza S, Li R. Sensitivity and specificity of information criteria. (Methodology Center Technical Report, No 12-119). University Park, Pennsylvania: The Methodology Center, The Pennsylvania State University; 2012.

25. Yang C, Yang C. Separating latent classes by information criteria. J Classif. 2007;24: 183-203.
26. Berglund P. Latent class analysis using PROC LCA. Available from http://support.sas.com/resources/papers/proceedings16/5500-2016.pdf Accessed on 2 February 2017.

27. World Health Organization. BMI classification. Available from: http://apps.who. int $/$ bmi /index.jsp? introPage=intro_3 html Accessed on 10 July 2017.

28. Instituto Nacional de Estadísticas. País y regiones por áreas urbana-rural: actualización población 2002-2012 y proyecciones 2013-2020. Available from: http://historico.ine.cl/canales/chile_estadistico/familias/demograficas_vitales.php Accessed on 10 March 2017.

29. Lanza S, Dziak J, Huang L, Wagner A Collins L. LCA Stata plugin users guide (Version 1.2). University Park, Pennsylvania: The Methodology Center, The Pennsylvania State University; 2015.

30. Subar A, Freedman L, Tooze J, Kirkpatrick $S$, Boushey C, Neuhouser $M$, et al. Addressing current criticism regarding the value of self-report dietary data. J Nutr. 2015;145:2639-45.

31. Atkin A, Gorely T, Clemes S, Yates T, Edwardson C, Brage S, et al. Methods of measurement in epidemiology: sedentary behaviour. Int J Epidemiol. 2012;41(5): 1460-71.

32. McGill R, Anwar E, Orton L, Bromley H, Lloyd-Williams F, O'Flaherty M, et al. Are interventions to promote healthy eating equally effective for all? Systematic review of socioeconomic inequalities in impact. BMC Public Health. 2015;15: 457-71.

33. Beauchamp A, Backholer K, Magliano D, Peeters A. The effect of obesity prevention interventions according to socioeconomic position: a systematic review. Obes Rev. 2014;15(7):541-5.

34. Peña S. Santiago sano: salud en todas las políticas para la reducción de ECNTs. Available from: http://web.minsal.cl/ sites / default/files/Santiago_Sano_ Salud_reduccion.pdf Accessed on $1 \overline{1}$ October 2017.

35. World Health Organization. Populationbased prevention strategies for childhood obesity: report of a WHO forum and technical meeting. Geneva: WHO; 2009.

Manuscript received on 14 October 2017. Revised version accepted for publication on 11 January 2018. 
RESUMEN

Identificación de pautas poco saludables de alimentación y actividad física en cuatro países de la Región de las Américas: un análisis de clases latentes

Palabras clave
Objetivos. Determinar conglomerados de personas que presentan comportamientos similares con respecto a la salud en materia de alimentación, actividad física y vida sedentaria en cuatro países de la Región de las Américas: Brasil (2013), Chile (2009), Estados Unidos de América (2013) y México (2012). Esto permite determinar cuáles de estos comportamientos se presentan simultáneamente, así como las características demográficas y sociodemográficas propias de cada conglomerado.

Métodos. Los datos a nivel individual que se analizaron se obtuvieron de entrevistas nacionales de salud y encuestas sobre exámenes de salud en Brasil, Chile, Estados Unidos y México para diferentes períodos. Se evaluaron los comportamientos de cada persona con respecto a la salud a partir de directrices de actividad física internacionales y directrices alimentarias nacionales. Se realizó un análisis de clases latentes para clasificar a los personas en conglomerados basados en dichos comportamientos, seguido de regresiones polinómicas para determinar las características de los integrantes de cada clase.

Resultados. En términos generales, la mayor parte de las personas pertenecían a las clases caracterizadas por una alimentación promedio o insalubre, pero con niveles suficientes de actividad física. Sin embargo, hay grandes diferencias entre los distintos países y grupos poblacionales. Los hombres con las características socioeconómicas más altas tenían más probabilidades en general de pertenecer a la clase menos saludable de cada país.

Conclusiones. Los resultados de este análisis apoyan la ejecución de acciones de políticas públicas más refinadas, dirigidas a determinados comportamientos nocivos en diferentes grupos poblacionales, definidos por género, grupo etario, nivel socioeconómico y, hasta cierto punto, lugar de residencia. Las próximas intervenciones deben dirigirse a los grupos poblacionales en riesgo establecidos en este artículo.

Epidemiología; dieta; estilo de vida; ejercicio; Américas.
RESUMO

Identificar padrões de alimentação pouco saudável e atividade física em quatro países das Américas: análise de classes latentes

Palavras-chave
Objetivos. Determinar aglomerados de indivíduos com comportamentos de saúde semelhantes quanto à alimentação, atividade física e sedentarismo em quatro países das Américas: Brasil (2013), Chile (2009), México (2012) e Estados Unidos (2013) a fim de determinar os comportamentos que ocorrem simultaneamente e as características demográficas e sociodemográficas associadas a cada aglomerado.

Métodos. Os dados ao nível do indivíduo analisados no estudo foram obtidos em entrevistas de saúde nacionais e pesquisas de saúde realizadas no Brasil, Chile, México e Estados Unidos em diferentes períodos. Os comportamentos de saúde de cada indivíduo foram avaliados segundo as diretrizes internacionais de atividade física e as diretrizes nacionais de alimentação. Foi realizada uma análise de classes latentes para classificar os indivíduos em aglomerados de acordo com os comportamentos, seguida da análise por regressão polinômica para determinar as características destes comportamentos em cada classe.

Resultados. A maioria dos indivíduos pertencia a classes caracterizadas por alimentação média ou pouco saudável, porém com nível suficiente de atividade física. No entanto, existem grandes diferenças entre os países e os grupos populacionais. Verificou-se maior probabilidade de os indivíduos do sexo masculino de nível socioeconômico mais alto pertencerem à classe menos saudável em cada país.

Conclusões. Os achados desta análise apoiam a implementação de ações de política mais apuradas dirigidas a determinados comportamentos pouco saudáveis em diferentes grupos populacionais, definidos por gênero, faixa etária, condição socioeconômica e, em certa medida, local de residência. As populações em risco identificadas no estudo devem ser o principal alvo de intervenções imediatas.

Epidemiologia; dieta; estilo de vida; exercício; Américas. 